\title{
Partida de ajedrez en el Martirio de Santa Olalla de F. García Lorca: sinónimos contextuales del blanco y negro
}

\author{
Chess Game in the Martyrdom of Santa Olalla \\ by F. García Lorca: Contextual Synonyms \\ for «Black» and «White»
}

\author{
Roxana Díaz \\ Universidad Estatal de San Petersburgo \\ pajaro@mail.ru \\ ORCID iD: https://orcid.org/0000-0002-2878-6549 \\ Xenia Sokolova \\ Universidad Estatal de San Petersburgo \\ sokol.www@mail.ru \\ ORCID iD: https://orcid.org/0000-0002-9282-1484
}

\section{RESUMEN}

La presente investigación tiene como propósito el análisis del código de color como parte del código interior del texto. La oposición de los lexemas «blanco» y «negro», y sus sinónimos contextuales «nieve» y «noche», permite observar la fábula implícita del texto. En la estructura profunda del texto, la tortura de Santa Eulalia por los soldados romanos se interpreta como una partida de ajedrez. En la narración implícita del poema, esta partida es una metáfora de la persecución del pueblo inocente.

Palabras Clave: García Lorca; código interior; palabras clave; color; información implícita.

\section{ABSTRACT}

The article is devoted to the analysis of the color code as part of the internal code of the text. The opposition of the lexemes «white» and «black» and of its contextual synonyms «snow» and «night» allows us to observe the implicit fable of the text. In the profound structure of the text, the martyrdom of St. Eulalia, who was tormented to death by the roman soldiers, is interpreted as a chess game. In the implicit narrative of the poem this chess game is a metaphor for the persecution of the innocent people.

Key words: García Lorca; Internal code; Keywords; Colour; Implicit information. 
La literatura filológica cuenta con numerosas obras dedicadas a la investigación de los textos de Federico García Lorca y de su Romancero Gitano en particular. Entre estas obras se destacan las de M. A. Arango (1998), E. Balmaseda Maestu (1998), L. Beltrán Fernández de los Ríos (1986), M. García-Posada (1998), P. Guerrero Ruiz y V. Dean-Thacker (1998), D. Harris (1993), M. Hernández (1981), J. Herrero (1992), L. Ospovat (1975), H. Ramsden (2008b), K.L. Selig (1992), E. Southworth (1999), G. V. Stepanov (1979), entre otros.

En esta investigación los textos lorquianos se analizan a través del código de colores. Para eso se aplica la metodología desarrollada en la Semiótica. Según la semiología, en cualquier texto existe dos tipos de codificaciones: la codificación interior (propia del texto) y la codificación exterior (que está fuera del texto). Esta última cuenta con numerosos contextos culturales: histórico, social, literario, biográfico, etc. La codificación exterior (decodificación) está relacionada con el problema hermenéutico de la interpretación del texto por su lector: las particularidades de sus conocimientos culturales, su competencia lingüística y sus asociaciones mentales (Dijk 2009; Eco 1990; Lotman 2011).

El color se usa de una manera muy amplia en todo tipo de simbología (Cirlot 1992: 135-141). Sin embargo, el color es, ante todo, un hecho social que no tiene significado universal. Todas las cuestiones relacionadas con el significado del color son culturalmente relativas (tómese como ejemplo la simbología funeral del blanco en la cultura japonesa). El color no se puede analizar fuera del contexto, fuera del tiempo y del espacio. El contexto social del color es el más importante, ya que es la sociedad la que crea el color: lo determina, le da su significado, construye sus códigos. No lo determina ni el artista, ni el científico, sino la sociedad misma. La connotación que lleva cualquier color no es natural ni artificial sino histórica, cultural (Pastoureau 2006: 125-128). Los experimentos de T. F. Karwoski (1944: 235-247) y R. M. Dorcus (1932) mostraron que las asociaciones que causa un color son distintas de las que causa su nombre.

TEXTO

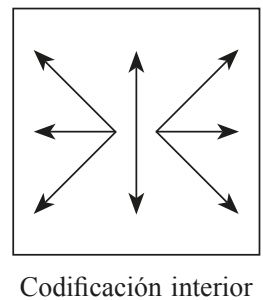

TEXTO

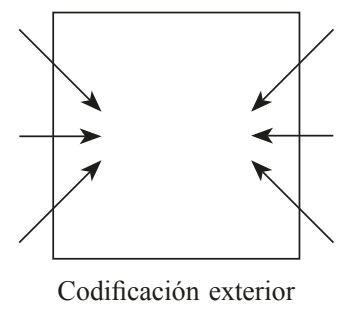

Gráfico 1. Codificación del texto. Fuente: Roxana Díaz

En cualquier tipo de texto (sea este un texto verbal o no verbal: pictórico, arquitectónico, musical, etc.) la codificación exterior es secundaria, mientras que 
la primaria es la codificación interior. El significado de los elementos del texto se codifica ante todo por su propio lenguaje, por su estructura interior. Todas las interpretaciones que se basan en la tradición, distintos tipos de contextos exteriores o lazos intertextuales, son secundarios y se aplican una vez terminado el análisis del texto basado en su composición interior (Pastoureau 2006: 125-131).

Asimismo, el color se codifica principalmente por su fuente (el mismo texto). El color en el texto se opone, ante todo, a otros colores (o a su ausencia) (Pastoureau 2006: 125-131). Por ejemplo, en el Romancero, el «pelo verde» (Romance sonámbulo, v. 7) puede oponerse al «negro pelo» (Romance sonámbulo, v. 71), y los dos al pelo de color marcado de una manera implícita «bajo su mata de pelo» (La casada infiel, v. 22) $)^{1}$. Las imágenes pueden aparecer en el mismo texto como en el caso del «pelo verde» y «negro pelo» (Romance sonámbulo, vv. 7, 71) o en un texto distinto del mismo libro «bajo su mata de pelo» (La casada infiel, v. 22). Por extensión, el objeto con color presente y color ausente puede oponerse a sí mismo en otro libro del autor o incluso en los textos de otros autores.

Al mismo tiempo, el «pelo verde» (Romance sonámbulo, v. 7) puede oponerse a la «verde baranda» (Romance sonámbulo, v. 72) en los marcos del mismo texto o a las «venas verdes» (Martirio de Santa Olalla, v. 27) en otro texto del libro. En este caso el color sirve no para diferenciar los mismos objeto son para establecer lazos asociativos e intertextuales entre los distintos objeto del mismo texto o de los distintos textos del autor y, por extensión, a los textos de otros autores.

La codificación interior del texto está estrechamente relacionada con su estructura profunda (en adelante EP). Si la estructura superficial (en adelante ES) del texto se observa con facilidad, la EP está fuera del alcance directo y puede observarse solo de una manera indirecta mediante el análisis de la ES. Las dos estructuras tienen la relación de la idea y su forma en la filosofía de lo ideal. De tal modo que la idea no observada de la manera directa corresponde a la EP, y la forma que es su continuación materializada es igual a la ES.

Estructura profunda Idea

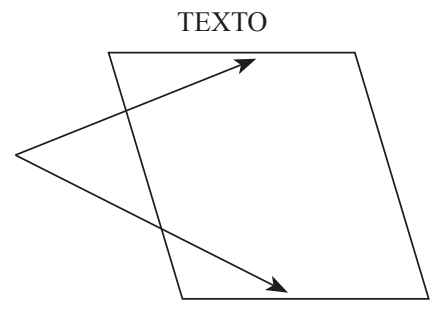

Estructura superficial Forma

GRÁfico 2. Estructura del texto. Fuente: Roxana Díaz

${ }^{1}$ La «mata» es una planta (DRAE 2014: 1423), una indicación implícita de color verde. Aunque explícitamente «mata de pelo» significa «conjunto o gran porción de la cabellera» (DRAE 2014: 1423). 
En la ES existen las llamadas posiciones fuertes del texto que son: la posición inicial/final del enunciado/verso/frase/capítulo/libro (o sea, del texto analizado o de su fragmento); el marco del texto (su nombre, dedicatoria, epígrafe, notas del autor, el nombre del autor en la cubierta, etc.); los nombres de los caracteres; palabras clave (Lotman 2011).

Estas últimas son las palabras más características del texto. No se trata de la frecuencia de su uso, ya que en este caso dominarían los pronombres, conectores, preposiciones y otras palabras que pueden resultar clave solo en casos excepcionales. Las palabras clave son las palabras más características del texto que pueden reflejar las particularidades de la EP.

TEXTO

Estructura profunda

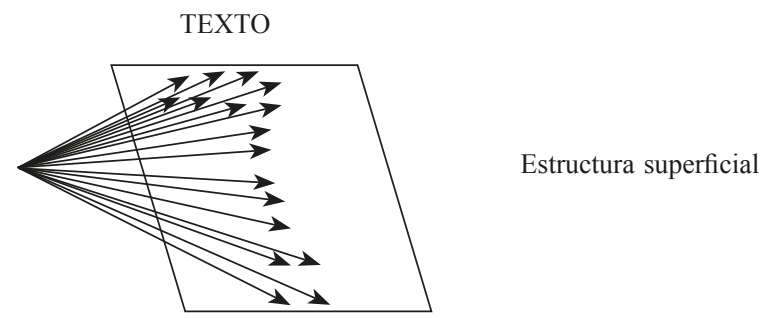

GrÁfico 3. Palabras clave. Fuente: Roxana Díaz

Según nuestra investigación, el color que ocupa un lugar significante en la obra de Lorca puede marcar estas palabras clave. A veces el propio nombre del color puede resultar una de estas palabras (como en el caso del famoso Romance Sonámbulo: «Verde que te quiero verde»).

En sus versos Lorca aplica una amplia gama de colores. M. Grossman en su investigación determina nueve colores como colores básicos de la lengua española. Los colores básicos normalmente corresponden a los hiperónimos en el sistema lexicográfico: blanco, negro, gris, amarillo, rojo, verde, azul, morado, marrón (Grossman 1982: 74). De estos nueve colores Lorca usa solo los primeros siete: blanco (127 usos), negro (98), verde (98), azul (62), gris (42), rojo (39), amarillo (34) (Díaz Camino 2013). La aplicación del color marrón y violeta en la obra de Lorca es muy reducida. Según nuestros estudios, en 195 de los 304 poemas publicados, Lorca aplica 502 hiperónimos de color expresados con adjetivos y sus derivados (aproximadamente 1,55 colores por poema) (ibídem). Como se observa, el primer lugar lo ocupa el color blanco, mientras que el negro y el verde comparten el segundo. Estos tres colores forman una triada lorquiana: blanco - negro - verde (comp. con la triada arcaica: negro - blanco - rojo) (Pastoureau 2006: 125-131). 


\begin{tabular}{|l|c|c|c|c|c|c|c|c|}
\hline \multicolumn{7}{|c|}{ LIBROS DE POEMAS (502 hiperónimos de color en 195 de 304 poemas publicados) } \\
\hline $\begin{array}{l}\text { Libro de poemas (1921) } \\
67 \text { poemas }\end{array}$ & 31 & 26 & 20 & 37 & 7 & 16 & 1 & 138 \\
\hline $\begin{array}{l}\text { Poema del Cante jondo } \\
\text { (1921) }\end{array}$ & 14 & 11 & 6 & 1 & 2 & 4 & 11 & 49 \\
11 ciclos, 56 poemas & blanco & negro & verde & azul & gris & rojo & amar & total \\
\hline $\begin{array}{l}\text { Primeras canciones } \\
\text { 1922) } \\
11 \text { poemas }\end{array}$ & 6 & 2 & 2 & 1 & - & 3 & 2 & 16 \\
\hline $\begin{array}{l}\text { Canciones (1921-1924) } \\
11 \text { ciclos, 86 poemas }\end{array}$ & 28 & 13 & 29 & 9 & 14 & 9 & 9 & 111 \\
\hline $\begin{array}{l}\text { Romancero gitano } \\
\text { (1924-1927) } \\
18 \text { poemas }\end{array}$ & 12 & 12 & 32 & 2 & 4 & 3 & 4 & 69 \\
\hline $\begin{array}{l}\text { Poeta en Nueva York } \\
\text { (1929-1930) 10 ciclos, } \\
35 \text { poemas }\end{array}$ & 26 & 29 & 4 & 13 & 8 & 4 & 6 & 90 \\
\hline $\begin{array}{l}\text { Llanto por Ignacio } \\
\text { Sánchez Mejías (1935) } \\
4 \text { poemas }\end{array}$ & 4 & 2 & 1 & - & 2 & - & - & 9 \\
\hline $\begin{array}{l}\text { Seis poemas gallegos } \\
\text { (1935) } \\
6 \text { poemas }\end{array}$ & - & 2 & 2 & - & 2 & - & - & 6 \\
\hline $\begin{array}{l}\text { Diván Tamarit (1936) } \\
\text { 2 ciclos, 21 poemas }\end{array}$ & 6 & 1 & 2 & 1 & 3 & - & 1 & 14 \\
\hline Total & 127 & 98 & 98 & 64 & 42 & 39 & 34 & 502 \\
\hline
\end{tabular}

TABla 1. Color en los libros de poemas de Lorca

En el Romancero gitano el color está todavía más concentrado. En 18 romances se usa 69 hiperónimos de color y 26 hipónimos (matices de los colores básicos), o sea 3,83 colores por poema. Los colores aplicados forman la siguiente secuencia: verde (32 usos), blanco (12), negro (12), gris (4), amarillo (4), rojo (3), azul (2) (Díaz Camino 2014).

El verde domina en la gama colorífica del Romancero ocupando la mitad de los hiperónimos de color del libro (32 de 69 usos). Según las investigaciones este color forma la antítesis principal del Romancero verde - rojo (Díaz Camino 2013). Los antónimos blanco y negro forman la antítesis blanco - negro, segunda por su importancia (sendos hiperónimos aparecen en 12 menciones). La antítesis acromática se amplifica con hipónimos de estos colores: oscuro (6 usos), moreno (6), azabache (1), pálido (1). También se extiende con sus sinónimos contextuales que en los contextos determinados se usan como designaciones de estos colores: carbón, plomo, plata, estaño, noche, nieve, luz, entre otros (Sokolova 2014: 404; Dumitrescu 1974: 346). 
En el Romancero la antítesis blanco - negro es una mezcla complicada de dos códigos acromáticos: el arcaico negro - blanco que remonta a los símbolos del cante jondo y el código cristiano blanco - negro. En el cuerpo principal del Romancero (los 15 primeros romances) la antítesis blanco - negro entre otras aplicaciones se usa para designar la oposición entre la guardia civil que persigue a los gitanos (negro) y los ángeles que son la custodia de los perseguidos (blanco).

En el Martirio de Santa Olalla, que forma parte de los Tres romances históricos que concluyen el Romancero siendo su apéndice original, también se usa esta antítesis. En este apéndice también viene a simbolizar una persecución, pero no de los gitanos por la guardia, sino de los primeros cristianos (blanco) por los soldados romanos (negro).

Como se expone en adelante en el Martirio, esta persecución se representa en una imagen de la partida de ajedrez muy original. El acceso a esta metáfora complicada se consigue mediante varios niveles de decodificación léxica que recurre al uso de las designaciones de color tanto lexicográficas como contextuales.

\section{EL PRIMER NIVEL DE CODIFICACIÓN: ANTÓNIMOS LEXICOGRÁFICOS «BLANCO»Y « «NEGRO». CÓDIGO CRISTIANO: LA LUZ Y LAS TINIEBLAS}

El Martirio de Santa Olalla describe la tortura y la muerte de la mártir cristiana de origen español, Santa Eulalia (también conocida en el sur de España como Santa Olalla). Santa Olalla fue una joven que a la edad de trece años se negó a reconocer los ritos paganos de los romanos. Al confesar ser cristiana fue torturada y asesinada por los soldados romanos (Riesco Chueca 1995).

Esta historia la cuenta Lorca de una manera implícita y menciona solo algunos detalles. De tal manera las metáforas ejercen la función eufemística y sirven para evitar una imagen explícita y cruel. Este tipo de narración escondida lo admiró Lorca en la obra de Góngora:

Góngora tuvo un problema en su vida poética y lo resolvió. Hasta entonces, la empresa se tenía por irrealizable. Y es: hacer un gran poema lírico para oponerlo a los grandes poemas épicos que se cuentan por docenas. Pero ¿cómo mantener una tensión lírica pura durante largos escuadrones de versos? ¿Y cómo hacerlo sin narración? Si le daba a la narración, a la anécdota, toda su importancia, se le convertía en épico al menor descuido. Y si no narraba nada, el poema se rompía por mil partes sin unidad ni sentido. Góngora elige entonces su narración y se cubre de metáforas. Ya es difícil encontrarla. Está transformada. La narración es como un esqueleto del poema envuelto en la carne magnífica de las imágenes. Todos los momentos tienen idéntica intensidad y valor plástico, y la anécdota no tiene ninguna importancia, pero da con su hilo invisible unidad al poema (Federico García Lorca La imagen poética en don Luis de Góngora) (García Lorca 1962: 84). 
Según nuestras observaciones el color desempeña un papel importante en este tipo de narración implícita en la obra de Lorca y en el Martirio de Santa Olalla en particular. Si en las dos primeras partes del romance Panorama de Mérida y El martirio aparece una amplia gama cromática - verde (1 uso), rojo (2), amarillo (1), gris (1), blanco (1) - en la tercera Infierno y Gloria su uso está reducido a dos colores acromáticos: blanco (3) y negro (1).

\subsection{Blanco en significado «muerto»}

En la última parte del romance Olalla aparece ya ahorcada por los soldados romanos. Los tres usos del lexema «blanco» figuran en los contextos que describen a la Santa. En esta última parte del romance el nombre de Olalla se menciona cuatro veces ${ }^{2}$ dividiendo los versos en varios fragmentos:

\begin{tabular}{|l|}
\hline Olalla pende del árbol (v. 52) \\
\hline Olalla muerta en el árbol (v. 56) \\
\hline Olalla blanca en el árbol (v. 64) \\
\hline Olalla blanca en lo blanco (v. 72) \\
\hline
\end{tabular}

Tabla 2. Estructura del texto Martirio de Santa Olalla. Infierno y Gloria, vv. 51-74

En la primera aplicación el blanco viene a significar «muerto»: «Olalla blanca en el árbol» (v. 64). El uso del adjetivo en la posposición del sintagma nominal actualiza su significado literal. Aunque analizando el texto en versos hace falta tener en cuenta que la posición sintáctica del adjetivo en el sintagma nominal resulta relativo puesto a que está influido por muchos factores complementarios tales como su ritmo y rima (NGLE 2009: 997).

Sea como fuere, en este ejemplo el adjetivo blanco viene a actualizar su sentido literal e indica el color del cuerpo de la heroína. Este color con frecuencia se usa para describir a los muertos. Eso se debe a que el desangre provoca la pérdida del color rosa de la piel y en comparación con su color natural parece blanco. Así el significado contextual del sintagma «Olalla blanca» (v. 54) resulta «Olalla muerta». Este significado se intensifica por el contexto anterior: «Olalla pende del árbol» (v. 52), «Olalla muerta en el árbol» (v. 56).

El significado «muerta» se realza por ausencia de verbos en los últimos tres enunciados que son unas frases elípticas. Esas últimas se refieren a la frase

2 Total el nombre de Olalla se menciona siete veces en el poema, igual que el nombre de la princesa Thamar, heroína del último poema Thamar y Amnón. 
«Olalla pende del árbol» (v. 52) en la que el verbo se menciona y son sus variantes elípticas:

\begin{tabular}{|l|}
\hline Olalla pende [viva] del árbol (v. 52) \\
\hline Olalla [pende] muerta en el árbol (v. 56) \\
\hline Olalla [pende] blanca en el árbol (v. 64) \\
\hline Olalla [pende/está] blanca en lo blanco (v. 72) \\
\hline
\end{tabular}

TABLA 3. Reconstrucción predicativa del texto Martirio de Santa Olalla. Infierno y Gloria, vv. 51-74

En los enunciados elípticos se supone la presencia implícita del verbo «pender». Mientras que la frase referencial supone presencia implícita del adjetivo «viva» u otro con el sentido «todavía viva» o «recién ahorcada». Así que los adjetivos «muerta»y «blanca» se oponen a este adjetivo implícito de la primera frase.

A parte del Martirio, los enunciados sin núcleo verbal que recurren al color explícito se usan en el Romance sonámbulo: «verde viento, verdes ramas» (vv. 2, 62, 84), «verde carne, pelo verde» (vv. 7, 23, 75), «cara fresca, negro pelo» (v. 71), entre otros (Díaz Camino 2013). Estos enunciados sirven para describir el hundimiento y la percepción del mundo desde el punto de vista de la joven ahogada. Según las investigaciones de E. Balmaseda Maestu son ejemplos de zeugma que intensifica la narración en el romance (1998: 16).

En ambos romances la ausencia del verbo sirve para crear una imagen de los muertos para los que el tiempo ya se ha parado. La imagen explícita del tiempo parado surge en el Romance de la guardia civil española: «los relojes se pararon» (v. 77). Teniendo en cuenta que, en español, la información temporal es aportada principalmente por el verbo, su ausencia ubica directamente a los sujetos fuera del tiempo. En ambos romances los enunciados sin núcleo verbal sirven para crear la imagen de los muertos: de la joven ahogada en el Romance sonámbulo y de la ahorcada en el Martirio.

El código cromático de los enunciados sin núcleo verbal contiene no solo los colores explícitos sino los implícitos también. En las frases se aplican varios sinónimos contextuales de color. Así, el color negro se transmite mediante la mención de árbol: «Olalla pende del árbol» (v. 52). Normalmente el árbol supone una designación contextual del color verde por su copa. Sin embargo, en este caso se trata de un árbol sin hojas por la temporada de invierno: «Nieve ondulada reposa» (v. 51). Además en la primera parte del romance se mencionan los árboles sin hojas: «Medio monte de Minervas / abre sus brazos sin hojas» (vv. 5-6).

Entones el marcado color negro del tronco del árbol sirve para la designación contextual de este color. En su investigación L. Beltrán Fernán- 
dez de los Ríos también llega a la misma conclusión (1986: 234). Una codificación semiótica de las relaciones establecidas entre el Sujeto y el Predicado en estos cuatro enunciados tiene un aspecto siguiente:

\begin{tabular}{|l|l|l|l|l|}
\hline Olalla pende del árbol (v. 52) & negro - negro & $0-0$ & & \\
\hline Olalla muerta en el árbol (v. 56) & blanco - negro & $1-0$ & & \\
\hline Olalla blanca en el árbol (v. 64) & blanco - negro & $1-0$ & & \\
\hline Olalla blanca en lo blanco (v. 72) & blanco - blanco & $1-1$ & & \\
\hline
\end{tabular}

Tabla 4. Codificación cromática. Antónimos lexicográficos. Martirio de Santa Olalla. Infierno y Gloria, vv. 51-74

Como se observa tanto el sujeto como el predicado del enunciado básico vienen a cambiar su color al contrario: negro implícito al blanco explícito. Lo que simboliza la transformación de la joven martirizada y ahorcada en una santa cristiana y su tránsito del infierno metafórico de sus torturas terrestres (negro) a su glorificación celestial (blanco).

\subsection{Blanco en significado «cubierto de nieve»}

Al mismo tiempo el adjetivo «blanca» significa «cubierta de nieve»:

Nieve partida comienza.

Olalla blanca en el árbol (vv. 63-64)

La frase «nieve partida comienza» (v. 63) puede interpretarse como «empieza a nevar» y así el cuerpo de Olalla se cubre con nieve. Este significado del blanco también viene a significar «muerto», porque la nieve se derrite en contacto con el cuerpo humano por su calor. Y se queda intacto solo en el cuerpo frío, o sea, muerto.

Esta imagen se refiere a la parte de la hagiografía de Santa Olalla, aludiendo a la escena cuando después de las torturas su cuerpo ya muerto lo echaron desnudo en el suelo. Sin embargo, de repente cayó la nieve y cubrió el cuerpo de la Santa (Riesco Chueca 1995).

La imagen de la nieve como protección divina se personaliza en la imagen de la guardia celestial:

Escuadras de níquel juntan

los picos en su costado (vv. 65-66)

La escuadra en el lenguaje militar significa una «unidad menor en las fuerzas militares, constituida por un corto número de soldados a las órdenes de 
un cabo» (DRAE 2014: 936). Asimismo puede referirse a los soldados romanos a pie de la Cruz que se jugaron a los dados la túnica inconsútil de Jesús (Mt 27: 35; Mc 15: 24; Lc 23: 34; Jn 19: 23-24). Estos soldados se mencionan en la primera parte del poema:

mientras juegan o dormitan

viejos soldados de Roma (vv. 3-4)

Mientras que «Olalla blanca en el árbol» (v. 64) es una alusión a Cristo Crucificado. Los picos cruzados pueden referirse a los picos de dos soldados: uno con caña y esponja con la que se le ofrece a Jesús la hiel y el vinagre (Mt 27: 48; Mc 15: 36; Lc 23: 36; Jn 19: 29), otro con lanza infligiendo en el costado «las cinco llagas de Cristo» (Jn 19: 34) mencionadas en el romance $L a$ monja gitana (v. 19). La segunda implícitamente marca la hora de la muerte. En la iconografía los picos de dos soldados a menudo se representan en la misma imagen ${ }^{3}$. Asimismo, al inicio del poema aparece la alusión a la corona de espinas de Jesucristo en los versos:

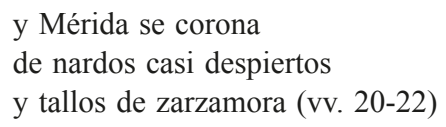

Las espinas de la zarzamora en la imagen de la madrugada es una alusión a la corona de espinas de la mártir como la de Jesucristo. Los nardos de la madrugada resultan también la alusión a su inocencia, marcada con la determinación «casi despiertos» (v. 21). El color blanco de la nieve y de las flores simboliza la pureza y la virginidad de Santa Olalla (Hernández 1981: 26), que, según su hagiografía, era una virgen de 12-14 años (Riesco Chueca 1995). En general, el romance lleva muchas alusiones a las Pasiones de Cristo detalladamente analizadas por H. Ramsden (2008b: 99-104).

Entonces la imagen de «Olalla blanca» (vv. 64, 72) significa tanto el cuerpo blanco de la muerta como el cuerpo cubierto de nieve. Al mismo tiempo, esa imagen alude a la iconografía de los santos que en las imágenes religiosas suelen presentarse vestidos de blanco, como Jesucristo en la tradición iconográfica de la Transfiguración ${ }^{4}$.

${ }^{3}$ Agradecemos en este punto los comentarios de uno de los evaluadores anónimos, que ofreció una interpretación renovada de este pasaje relacionándolo con la imagen de la escarcha. Esta puede estar basada en la semejanza de los rayos de la escarcha con los picos de las escuadras de níquel. En este caso, el lexema «níquel» lleva el sema «blanco»y «brillante» (DRAE 2014: 1539), atributos tanto de la nieve como del hielo.

${ }^{4}$ Varios autores marcan la influencia que ha tenido la cultura renacentista en las imágenes de Lorca, sobre todo, en su Romancero (Ramsden 2008a: 47-50; Southworth 1999: 97-101). 


\subsection{Blanco en significado «santo»}

En la cultura cristiana el color blanco viene a significar «puro», «santo» (Cirlot 1992: 140) y con frecuencia se aplica en las imágenes iconográficas de la Gloria y de la Transfiguración de Nuestro Señor. Este sentido se actualiza en la segunda mención del adjetivo «blanco» en los versos finales del romance que crean la imagen de la Gloria $^{5}$ de la Santa al final del Infierno y Gloria:

¡Saltan vidrios de colores! ${ }^{6}$

Olalla blanca en lo blanco.

Ángeles y serafines

dicen: Santo, Santo, Santo (vv. 71-74)

El significado «santo» se enfatiza con la mención de los ángeles, serafines y la aplicación directa de la palabra «Santo» en dos últimos versos (vv. 73-74). Los versos de Olalla en la Gloria que está «blanca en lo blanco» (v. 72) es una rima asonante al «Santo, Santo, Santo» (v.74) de la Misa Católica que Lorca había oído en latín en los años 30 (antes de la reforma del Concilio Vaticano II en 1962) ${ }^{7}$. Según M. Hernández, los dos últimos versos proceden de una canción religiosa que se cantaba en la casa de Lorca como menciona su hermana Isabel (Hernández 1981: 26).

En estos versos observamos unas alteraciones lexicográficas especialmente remarcables. En general, en el arte occidental la selección del color fue condicionada por la influencia del simbolismo cristiano, puesto que la Iglesia tenía su propia paleta de colores tradicionales. Los primeros matices que dependían de la temporada litúrgica aparecieron ya en el siglo IV. Cerca del año 1200 fueron sistematizados por el Papá Innocentius III en una paleta de colores que consistía del negro, blanco, rojo, verde y violeta. Estos colores se usan hasta nuestros días y tienen el nombre latín. El blanco — «albus»— se pone para las fiestas más importantes - la Navidad y la Pascua, así como para las fiestas de los santos (Fraser y Banks 2004).

No obstante, la palabra «albus» aplicada en la Vulgata en la escena de la Transfiguración fue traducida al español con el lexema «blanco»: «vestimenta

${ }^{5}$ Gloria en la doctrina cristiana significa «estado de los bienaventurados en el cielo, definido por la contemplación de Dios» (DRAE 2014: 1107).

${ }^{6}$ La imagen de los «vidrios de colores» (v. 71) es una obvia alusión a las vidrieras de las iglesias en las que aparecen las escenas de la vida de los santos así como las imágenes cristológicas. Compárense con «vidrieras de colores» que significa «vidriera formada por vidrios con dibujos coloreados y que cubre los ventanales de iglesias, palacios y casas» (DRAE 2014: 2241).

7 «Sanctus, Sanctus, Sanctus Dominus Deus Sabaoth. Pleni sunt caeli et terrae gloria tua» («Santo, santo, santo es el Señor, Dios del Universo. Llenos están el cielo y la tierra de tu gloria») (Urdeix 2006: 26-27). 
autem eius facta sunt alba sicut nix» (y sus vestiduras se volvieron blancas como la luz) (Mt 17:2 VUL); «et vestitus eius albus refulgens» (y su ropa se hizo blanca y resplandeciente) (Lc 9: 29 VUL); así como el lexema «cándido» en la misma escena: «et vestimenta eius facta sunt splendentia candida nimis velut nix qualia fullo super terram non potest candida facere» (y sus vestiduras se volvieron resplandecientes, muy blancas, tal como ningún lavandero sobre la tierra las puede emblanquecer) (Mc 9: 2 VUL) ${ }^{8}$. Ya en La Divina Comedia de Dante en la escena de la Gloria de Beatrice no se aplica el derivado de «albus» sino el germanismo «blank» (aunque conservando la aplicación de «candidus» ${ }^{9}$.

La imagen lorquiana de Santa Olalla en la Gloria se intensifica con la mención de una Custodia:

Una Custodia reluce

sobre los cielos quemados (vv. 67-68)

Según M. García-Posada (1998: 40), «como en los autos de Calderón, la Custodia brilla con luz esplendente, solar, adorada por los ángeles y serafines [...] esta Epifanía final anuncia, por otra parte, la obsesión eucarística».

En los términos religiosos una «custodia» significa: «en el culto católico, pieza de oro, plata u otro metal, donde se expone la hostia consagrada a la adoración de los fieles» (DRAE 2014: 700) y por extensión metonímica «templete o trono, generalmente de plata y de grandes dimensiones, donde se coloca la custodia» (DRAE 2014: 700). En estos contextos supuestamente se trata de una custodia hecha de plata. Como la plata pertenece al campo semántico del color blanco: «elemento químico metálico... de color blanco, brillante...» (DRAE 2014: 1733) en estos versos una «custodia» (v. 67) resulta una designación contextual del blanco.

Si se tratara de una custodia hecha de oro, este también tendría su significado contextual «luz», «claridad». En el Diccionario de la Real Academia Española el oro se adscribe al campo semántico del color amarillo: «elemento químico metálico... de color amarillo brillante» (DRAE 2014: 1588). Pero, igual como la plata, contiene el sema «brillante» que los atribuye al campo semántico de la luz. Según nuestras observaciones en el Romancero Lorca aplica el lexema «oro» como sinónimo del blanco.

La oposición explícita del color a la luz se expone en los versos:

\footnotetext{
${ }^{8}$ A todos esos casos de uso del lexema «blanco» en la traducción española, en el ori-

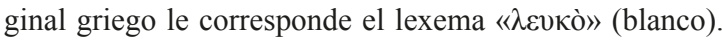

9 «Le facce tutte avean di fiamma viva, / e l'ali d'oro, e l'altro tanto bianco, / che nulla neve a quel termine arriva» (Dante Alighieri, La Divina Commedia, Paradiso, Canto $X X X I, v v, 13-15)$.
} 
¡Saltan vidrios de colores!

Olalla blanca en lo blanco (vv. 71-72)

Como el lexema «colores» se opone al «blanco» este último pierde su significado de color activado en los versos anteriores y viene a significar «luz».

Por una de las teorías en los albores del desarrollo del idioma las designaciones claro y oscuro (blanco y negro) se distinguen las primeras formando la oposición entre la «luz»y su ausencia, la «oscuridad» (Wierzbicka 1990; Berlin y Kay, 1969). Les sigue la designación «rojo» oponiéndose en este caso no al color negro (la ausencia de la luz), sino al blanco, creando así una oposición «luz» - «color». Simbolizando así el rojo todo el color en su generalidad (Kolesov 1986).

Este lazo histórico entre los conceptos de «color» en general y «rojo» como su representación más característica se conserva en la palabra «colorado» como su primer significado: «Colorado. 1. adj. rojo. Tonos colorados. Tierra colorada» (DRAE 2014: 575).

La designación «de colores» en este caso viene a significar «todo el color en general» como la característica de este mundo. La cancelación del color como su atributo «iSaltan vidrios de colores!» (v. 71) simboliza la transición al otro mundo. En estos contextos las designaciones «blanco» y «negro» pierden su significado «color» y se usan solo en su significado valorativo-diferenciador y de este modo se convierten en una connotación interior del texto que sirve para transmitir la posición implícita del autor. La imagen de la luz sagrada se intensifica con el fondo blanco de la imagen de la Santa «en lo blanco» (v. 72).

\subsection{Blanco en significado «cielos»}

La idea del color blanco resplandeciente en la Gloria de Santa Olalla se enfatiza con el uso del artículo neutro «lo». La substantivación contextual del hiperónimo «blanco» transmite la idea abstracta del color: «Olalla blanca en lo blanco» (v. 72). El adjetivo substantivado «lo blanco» es sinónimo del sustantivo «blancura» (Alarcos Llorach 2009: 98). De tal manera se cree la imagen del fondo blanco, o sea el fondo lleno de Luz sacra. En este contexto «lo blanco» significa «luz», «cielos», «paraíso». Esta imagen se intensifica con otros sinónimos contextuales del blanco «cielos quemados» (v. 68):

Una Custodia reluce

sobre los cielos quemados (vv. 67-68)

Según las definiciones del Diccionario de la Academia Real Española, el participio «quemado» y el verbo «quemar» pueden asociarse con colores rojo y negro (DRAE 2014: 1826). Sin embargo, la codificación interior del texto 
alude a que se trata del color blanco. Este significado del adjetivo se realiza en lenguaje profesional de los fotógrafos: «cielos quemados» significan los «cielos cubiertos con las nubes» que no permiten ver el sol. Lo que corresponde a su significado contextual que supone una designación contextual del blanco. De tal manera el significado contextual de «lo blanco» «cielos» corresponde al color de los cielos quemados y los dos vienen a significar no solo el claro del cielo al amanecer, sino «los cielos» en su sentido metafórico «paraíso».

La imagen de la Santa en el fondo luminoso simboliza su glorificación enfatizada con el mismo nombre de la tercera parte Infierno y Gloria. Esa imagen iconográfica se completa con aparición de los ángeles al final del poema:

Ángeles y serafines

dicen: Santo, Santo, Santo (vv. 71-74)

Los versos «una Custodia reluce» (v. 67) también puede asociarse con la imagen de los ángeles puesto que recuerda a la frase hecha «ángel custodio» que es un «ángel que Dios tiene asignado a cada persona para su guarda...» (DRAE 2014: 147). Al mismo tiempo, la imagen de la custodia sirve para aludir a las torturas de la mártir al actualizar otro significado de la palabra: «persona o escolta encargada de custodiar a un preso» (DRAE 2014: 700).

A diferencia de la imagen de Olalla realizada en enunciados sin núcleo verbal, en la descripción de las tropas celestes se usan los verbos en presente «juntan» (v. 65), «reluce» (v. 67).

\subsection{Negro en significado «desastre»}

Al color blanco de la víctima y los ángeles que la acompañan, se le opone el negro de sus verdugos romanos. Los primeros pertenecen a las tropas celestiales y los últimos crean la imagen de las fuerzas infernales:

Negros maniquíes de sastre

cubren la nieve del campo

en largas filas que gimen

su silencio mutilado (vv. 59-62)

La preposición del hiperónimo «negro» actualiza su sentido metafórico «siniestro», «amenazante» (NGLE 2009: 997). Este significado se enfatiza con el parónimo contextual «de sastre» / «desastre» en el verso «negros maniquíes de sastre» (v. 59). El sentido contextual de la metáfora es «los soldados romanos parecidos a los maniquíes insensibles que aluden a una catástrofe inevitable».

Esa imagen de las tropas infernales se refuerza con el sinónimo contextual del negro «tinta»: 
Tinteros de las ciudades

vuelcan la tinta despacio (vv. 57-58)

Al mismo tiempo el lexema «tinta» puede designar el color rojo (DRAE 2014) que puede designar la sangre en sentido metafórico. De modo que esta imagen puede significar «los soldados romanos pasan por la ciudad derramando la sangre de sus ciudadanos». Lo que completa la imagen de un ejército infernal. El mismo nombre de la tercera parte del poema Infierno y Gloria enfatiza la imagen de la lucha entre las tropas celestiales e infernales.

\section{SEgundo Nivel DE CODIFICACIÓN: ANTÓNIMOS CONTEXTUALES «NIEVE» (BLANCO) Y «NOCHE» (NEGRO). PARTIDA DE AJEDREZ}

El juego de ajedrez que había entrado en Europa con los árabes a través de España en la Edad Media llegó a simbolizar la oposición entre las fuerzas de Dios y las de Diablo (Pastoureau 2006: 297-320). Esa imagen se remonta a los versos del Nuevo Tesamento: «...la luz brilló en las tinieblas, y las tinieblas no la comprendieron» (Jn 1:5).

\subsection{Tablero de ajedrez}

En la tercera parte del romance se aplican otros sinónimos contextuales del blanco y negro «nieve» (vv. 51, 63) y «noche» (v. 55). La palabra «nieve» se aplica en la posición inicial (v. 51), o sea en una posición «fuerte». La alteración de las palabras «nieve» $\mathrm{y}$ «noche» en las posiciones iniciales de los versos crea una imagen del tablero de ajedrez:

\begin{tabular}{|l|l|l|l|}
\hline Nieve ondulada reposa (v. 51) & blanco & 1 & \\
\hline Noche tirante reluce (v. 55) & negro & 0 & \\
\hline Nieve partida comienza (v. 63) & blanco & 1 & \\
\hline
\end{tabular}

TABla 5. Codificación cromática. Antónimos contextuales. Martirio de Santa Olalla, Infierno y Gloria, vv. 51-74

Lorca se limita a tres alteraciones de las designaciones contextuales de color. M. Pastoureau explica que el ajedrez es un símbolo de eternidad. La estructura alternada de su tablero puede multiplicarse de una manera infinita. Aun así en la imagen visual del ajedrez son suficientes solo sus cuatro cuadros para dar una idea completa de su estructura con todas sus particularidades. La estructura abierta del ajedrez puede multiplicarse con una simple partenogéne- 
sis (2006: 297-320 $)^{10}$. Sin embargo, la particularidad de los textos en versos, con su estructura métrica y su ritmo riguroso, y la idea esencial de repetición surge con solo tres alteraciones.

La imagen del ajedrez se acentúa con la mención del término «partida»: «Nieve partida comienza» (v. 63).

También se enfatiza con la aplicación de la palabra «campo» que se usa en el lenguaje profesional de los jugadores de ajedrez:

Negros maniquíes de sastre

cubren la nieve del campo (vv. 59-60)

La misma palabra «ajedrez» se menciona en el Romancero al final del romance La monja gitana:

Pero sigue con sus flores, mientras que de pie, en la brisa,

la luz juega el ajedrez

alto de la celosía.

(Romancero gitano, La monja gitana, vv. 32-36)

Esta metáfora se basa en la comparación de la alteración de los cuadros negros y blancos del tablero de ajedrez con la alteración de las rayas de la luz y la sombra producidas por la celosía. Esta imagen se remonta a la concepción cristiana del ajedrez como una lucha entre la luz y las tinieblas (Pastoureau 2006: 297-320).

La partida de ajedrez puede simbolizar el tránsito de este mundo al otro (ibídem). De tal manera en el Martirio de Santa Olalla esta imagen es una metáfora en sentido amplio que representa la muerte de Olalla y su paso al mundo de ultratumba.

\subsection{Piezas blancas y negras}

La imagen de un tablero de ajedrez nos permite volver a interpretar el texto con la retrospectiva de una partida de ajedrez representada. De tal modo, los maniquíes siniestros de la guardia romana sirven para crear la imagen de las piezas negras de ajedrez. La imagen metafórica de los soldados romanos se basa no solo en el ajedrez como símbolo militar, sino también en la semejanza de las tropas uniformadas con los peones:

\footnotetext{
${ }^{10}$ Esta función la cumple el ajedrez en La Divina Comedia de Dante: «L'incendio suo seguiva ogne scintilla; / ed eran tante, che '1 numero loro / più che '1 doppiar de li scacchi s'inmilla» (Dante Alighieri, La Divina Commedia, Paradiso, Canto XXVIII, vv. 91-93).
} 
Negros maniquíes de sastre

cubren la nieve del campo (vv. 59-60)

A las piezas negras se les oponen las blancas:

Escuadras de níquel juntan

los picos en su costado (vv. 65-66)

En el diccionario de la lengua española «níquel» se define como un metal de color de plata: «elemento químico metálico..., del color y brillo de la plata...» (DRAE 2014: 1539). Mientas que la plata, como ya se ha mencionado, se considera un metal blanco (DRAE 2014: 1733). De tal manera «níquel» resulta una designación contextual de color blanco.

La imagen de las «escuadras de níquel» (v. 65) es una extensión metafórica de la imagen de la nieve que cubrió el cuerpo desnudo de la mártir. La nieve se interpreta como una custodia celestial que guarda el cuerpo de la santa. Al mismo tiempo la imagen «escuadras de níquel» (v. 65) en su sentido literal sirve para especificar la imagen del tablero de ajedrez, que tiene una forma cuadrada con escuadras metálicas en las equinas para sujetarlo ${ }^{11}$.

\subsection{El Peón Blanco (d2-d4) y la Reina Blanca (d7-d8)}

Con la retrospectiva de la imagen del ajedrez, Santa Olalla se reinterpreta como un peón blanco que tradicionalmente comienza la partida:

Nieve partida comienza.

Olalla blanca en el árbol (vv. 63-64)

«Olalla blanca» (v. 64) en este contexto puede significar «Olalla se convierte en el peón blanco que comienza la partida con un paso tradicional d2-d4» (cmpr. Lewis Carroll A través del espejo) (Carroll 2003).

En la última línea, el peón puede convertirse en una reina. La conversión normalmente viene seguida de un jaque mate (del árab. cl. «rey está muerto») (DRAE 2014: 1278) que significa una partida ganada. En este contexto el adjetivo substantivado «lo blanco» significa el alcance de la línea opuesta por el peón de «Olalla blanca» (v. 64) con el paso «d7-d8» (Carroll, 2003), su conversión en una reina y la victoria siguiente de los blancos:

¡Saltan vidrios de colores!

Olalla blanca en lo blanco (vv. 71-72)

${ }^{11}$ Uno de los significados de la «escuadra» es una «pieza de hierro u otro metal, con dos ramas en ángulo recto, con que se aseguran las ensambladuras de las maderas» (DRAE 2014: 936). 
La codificación semiótica de esta partida codificada en negro (0) - blanco (1) según el Sujeto (S) y el Predicado (P) de cada verso tiene el siguiente aspecto:

Infierno y Gloria

Nieve ondulada reposa.

Olalla pende del árbol.

Su desnudo de carbón

tizna los aires helados.

Noche tirante reluce.

Olalla muerta en el árbol.

Tinteros de las ciudades

vuelcan la tinta despacio.

Negros maniquíes de sastre

cubren la nieve del campo

en largas filas que gimen

su silencio mutilado.

Nieve partida comienza.

Olalla blanca en el árbol.

Escuadras de níquel juntan

los picos en su costado.

Una custodia reluce

sobre los cielos quemados

entre gargantas de arroyo

y ruiseñores en ramos.

¡Saltan vidrios de colores!

Olalla blanca en lo blanco.

Ángeles y serafines

dicen: Santo, Santo, Santo.

$$
\begin{gathered}
\mathrm{S}-\mathrm{P} \\
\text { negro }- \text { blanco }
\end{gathered}
$$

blanco - blanco

negro - negro

negro - negro

negro - negro

negro - blanco

blanco - negro

negro - negro

negro - negro

negro - negro

negro - blanco

negro - negro

negro - negro

blanco - blanco

blanco - negro

blanco - blanco

blanco - blanco

blanco - blanco

blanco - blanco

blanco - blanco

blanco - blanco

color - color
blanco - blanco
blanco - blanco
blanco - blanco
$0-1$

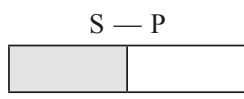

$1-1$

0-0

0-0

0-0

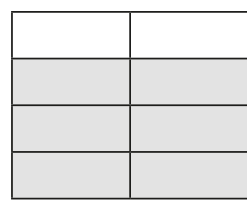

$0-1$

1-0

0-0

0-0

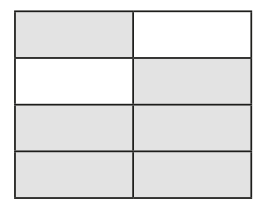

$0-0$

0-1

0-0

0-0

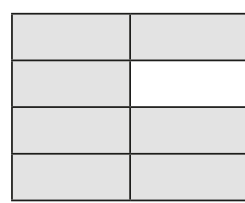

1-1

1-0

1-1

1-1

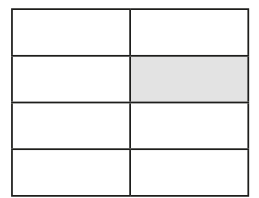

1-1

1-1

1-1

1-1

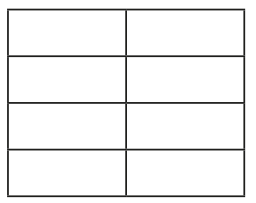

?-?

1-1

1-1

1-1

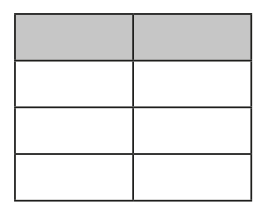

TABLA 6. Codificación cromática (sujeto - predicado) de Martirio de Santa Olalla. Infierno y Gloria, vv. 51-74 
La oposición en símbolos militares actualiza la división implícita entre el «amigo»y el «enemigo».

En el Romancero el tema del ajedrez, noble juego de los reyes, se opone al de naipes ${ }^{12}$, juego de azar, marcado en la Reyerta con el verde:

Una dura luz de naipe

recorta en el agrio verde

(Romancero gitano, Reyerta, vv. 5-6)

Las cartas simbolizan el juego con la vida, una vida arriesgada, un destino como casualidad. El tema del juego en el Martirio se activa con el verbo «jugar» en los versos iniciales de la primera parte del romance:

mientras juegan o dormitan

viejos soldados de Roma

(Romancero gitano, Martirio, vv. 3-4)

Como hemos mencionado, en este caso se trata de un juego a los dados ${ }^{13}$. A diferencia de los juegos de azar -como las cartas y los dados- que simbolizan el destino como casualidad, el ajedrez simboliza la vida como una lucha. En una de sus conferencias Lorca comparó al poeta andaluz con el poeta oriental que «siente a la vida como un tablero de ajedrez» (Federico García Lorca El cante jondo, primitivo canto andaluz) (1962: 1529).

\section{TERCER NIVEL DE CODIFICACIÓN: LO CROMÁTICO POR LO ACROMÁTICO. VERDE POR MORENO. Código LORQUIANO: CONECTORES INTERTEXTUALES}

A pesar de la referencia histórica del Martirio a la época de la persecución de los primeros cristianos por los soldados romanos, el poema da la impresión de una persecución de los gitanos por la guardia civil. Como ya se ha mencionado, el último se ubica entre los temas centrales del Romancero. Ese efecto de percepción puede explicarse con unos detalles del análisis lingüístico.

El color verde, que une los romances básicos del Romancero (los primeros 15 romances), no se menciona en los Tres romances históricos salvo el Martirio. De tal manera este último romance con su única aplicación del verde sirve

12 Sobre esta cuestión, destacamos la interpretación de uno de los evaluadores anónimos que señala la relación del verso «una dura luz de naipe» (v. 5) con la baraja francesa monócroma en blanco, negro y rojo, frente a la policromía de la baraja española (cf. la Oda a Salvador Dali): «Canto tu corazón astronómico y tierno, / de baraja francesa y sin ninguna herida» (Poemas Sueltos, Oda a Slvador Dali, vv. 92-93).

13 Algo que señalan también D. Harris y M. Hernández en sus comentarios (Harris 1993: 201; Hernández 1981: 25). 
para establecer lazos intertextuales entre los Tres romances y los primeros quince romances:

Un chorro de venas verdes

le brota de la garganta (vv. 27-28)

\subsection{Verde por moreno}

En los primeros quince romances el color verde se usa para crear una imagen generalizada del pueblo gitano. En muchos casos el verde se asocia con lo moreno ${ }^{14} \mathrm{o}$ incluso se aplica en lugar de este color ${ }^{15}$. La conexión de los colores verde y moreno se explicita en la descripción del gitano Antonio en la que los dos colores aparecen en un solo sintagma: «Moreno de verde luna» (Prendimiento de Antoñito, v. 5; Muerte de Antoñito, v. 21).

La imagen designa la piel «morena e iluminada por la luna». Eso se debe a que la piel morena de los gitanos bajo la luna adquiere un matiz verdoso (aceitunado, oliváceo). La imagen de la piel bronceada por la luna surge también en la carta de Lorca a José Bello: «iSi vieras cómo está Andalucía! Los gallos clavan banderillas de lujo en el testuz del amanecer y yo me pongo moreno de sol y de luna llena...» (Federico García Lorca, Carta a José Bello, verano de 1925) (1962:1650).

De tal modo, la imagen de «venas verdes» (v. 27) de Santa Olalla no solo alude al color moreno de su piel, sino la identifica como una gitana en el Romancero. La imagen gitanizada de la Santa queda comprobada por el mismo autor en su carta a J. Guillén en la que el romance se menciona como «Romance del martirio de la gitana Santa Olalla de Mérida» (ibíd.: 1579), asimismo la heroína Olalla se llama «gitana».

La imagen de «un chorro de venas verdes» (v. 27) se usa para designar la sangre derramada de la mártir y significa «un chorro de sangre». De una manera implícita esa imagen se opone a la de «sangre azul» en su significado «linaje noble» (DRAE 2014: 1969).

De tal manera en el Romancero se crea una imagen de los gitanos como la aristocracia de «sangre verde», «porque el gitano es lo más elevado, los más

${ }^{14}$ Esta combinación también tiene su contexto literario, por ejemplo, en la copla cervantina recogida por P. Henríquez Ureña en su Antología de la versificación rítmica (1919: 34): «Por un morenico de color verde / ¿Cuál es la fogosa que no se pierde?» (Miguel de Cervantes Saavedra, Rinconete y Cortadillo).

${ }_{15}$ Esta relación cromática puede tener también una explicación naturalista. En la piel morena de los gitanos las venas se ven de color verde y no de color azul como en la piel clara. Comp. con el color azul de las venas en la piel blanca en la imagen del «almidonado pecho de la nodriza (ese pequeño monte volcánico de estremecido de leche y venas azules)...» (Federico García Lorca Nanas infantiles) (1962: 52). 
profundo, más aristocrático de mi país, lo más representativo de su modo y el que guarda el ascua, la sangre y el alfabeto de la verdad andaluza y universal» (García Lorca 1994).

Al mismo tiempo en la simbología lorquiana el verde es el color de la muerte (Arango 1998: 141-142). La imagen amenazante de «sangre verde» se explicita en uno de sus textos: "Como poeta autentico que soy y seré hasta mi muerte, no cesaré de darme golpes con las disciplinas en espera del chorro de sangre verde o amarillo que necesariamente y por fe habrá mi cuerpo de manar algún día» (Federico García Lorca Imaginación, inspiración, evasión) (1962: 1548). En general, este color en la obra de Lorca, y en su Romancero en particular, es un símbolo complejo (García Lorca 1972: 135-139). Es el color «de las plantas vivas y de los cadáveres» (Arango 1998: 142), color de «vida, amor y muerte» (Lama 1997: 469). Como resumen Guerrero Ruiz y Dean-Thacker (1998: 81): «García Lorca jugó la transición cromática entre el modernismo y la generación del 27; pero García Loca no habla sólo de color, sino de una irrealidad simbólica y visionaria».

\subsection{Lazos intertextuales}

Entre los Tres romances el de Martirio quizás es el más unido con los romances básicos del Romancero. Es un romance que sigue el último de los romances básicos del libro y resulta su continuación lógica. Esta conexión está marcada con varios conectores intertextuales léxicos.

La imagen agitanada de Santa Olalla se explicita con la descripción de la gitana Rosa de los Camborios del Romance de la guardia civil española que sufre las mismas torturas que la mártir (Hernández 1981: 22):

El Cónsul pide bandeja para los senos de Olalla.

(Martirio de Santa Olalla, vv. 25-26)

Rosa la de los Camborios gime sentada en su puerta con sus dos pechos cortados puestos en una bandeja.

(Romance de la guardia civil española, vv. 105-108)

En la tradición iconográfica Santa Eulalia se representa con una bandeja con sus pechos cortados (Riesco Chueca 1995).

En la posición inicial del Martirio se menciona un caballo suelto que corre la calle sin jinete supuestamente asesinado:

Por la calle brinca y corre

caballo de larga cola

(Martirio de Santa Olalla, vv. 1-2) 
Un caballo malherido

llamaba a todas las puertas.

(Romance de la guardia civil española, vv. 29-30)

El color negro en la imagen de los «negros maniquíes de sastre» (v. 59) -en los que se convierten los «viejos soldados de Roma» (v. 4) en la última parte del Martirio- se usa para describir a la guardia civil en los romances básicos del Romancero:

Los caballos negros son.

Las herraduras son negras.

(Romance de la guardia civil española, vv. 1-2)

El color negro se usa en varios códigos acromáticos del Romancero. Sin embargo, en la anteposición al sustantivo el negro se aplica en la descripción de la guardia civil ${ }^{16}$ :

sus negras capas ceñidas

y los gorros en las sienes

(Preciosa y el aire, vv. 49-50)

El significado del negro en anteposición «amenazante», «siniestro» (NGLE 2009: 997) intensificado por el parónimo contextual «de sastre» — «desastre» en los «negros maniquíes de sastre» (v. 59) se explicita en la descripción de la guardia en el Romance de la guardia civil española:

Por las calles empinadas

suben las capas siniestras,

dejando detrás fugaces

remolinos de tijeras.

(Romance de la guardia civil española, vv. 89-92)

Las capas atribuidas a la guardia «suben las capas siniestras» (v. 90), «sobre las capas relucen» (v. 3) en el Romance de la guardia se describen como un traje elegante «sus negras capas ceñidas» (v. 49) en la Preciosa y el aire. Este sema de elegancia que contiene la imagen de las capas en el código interior del Romancero lo refleja también la imagen de los maniquíes proporcionados en los «negros maniquíes de sastre» (v. 59) en el Martirio.

La imagen de la tinta derramada sobre las capas en el Romance de la guardia se repite en el Martirio, pero ya como fuente de aparición de los soldados:

${ }^{16}$ Salvo la imagen del «negro pelo» (v. 71) del Romance sonámbulo en el que el color negro se convierte en el símbolo de la vida en la oposición interior al "pelo verde» que simboliza la muerte (Díaz Camino 2013). 
Sobre las capas relucen manchas de tinta y de cera.

(Romance de la guardia civil española, vv. 3-4)

Tinteros de las ciudades vuelcan la tinta despacio. Negros maniquíes de sastre cubren la nieve del campo (Martirio de Santa Olalla, vv. 57-60)

La imagen de las guardias que «avanzan de dos en fondo» (vv. 65, 69) en el Romance de la guardia se asemeja a la imagen de los maniquíes que se alinean en filas:

Negros maniquíes de sastre

cubren la nieve del campo

en largas filas que gimen

su silencio mutilado.

(Martirio de Santa Olalla, vv. 59-62)

El «silencio mutilado» de los maniquíes tiene su origen en el Romance de la guardia:

\author{
Jorobados y nocturnos, \\ por donde animan ordenan \\ silencios de goma oscura \\ y miedos de fina arena. \\ (Romance de la guardia civil española, vv. 9-12)
}

De ese modo, el uso constante del negro como atributo de la guardia civil asemeja la imagen de la guardia con la imagen de los «viejos soldados de Roma» (v. 4) que se interpretan como «negros maniquíes de sastre» (v. 59) en la última parte del Martirio.

El Martirio resulta una clara continuación del Romance de la guardia civil, algo que ya mostró J. Herrero en su análisis detallado del romance (1992). K.L. Selig señala la organicidad constructiva del Romancero y subraya que en este romance se desarrollan las imágenes del poema anterior (1992: 122). Lorca mismo explicita estos lazos en su carta a J. Guillén: «Ahora llega la guardia civil y destruye la ciudad... A veces, sin que sepa por qué, se convertirán en centuriones romanos... Una vez terminado este romance y el Romance del martirio de Santa Olalla de Mérida daré por terminado el libro» (1962: 1579).

De tal manera, el Martirio es una amplia metáfora que reinterpreta la tragedia que se desplegó en el Romance de la guardia civil española desde el punto de vista de los acontecimientos de la época de persecución de los primeros cristianos en el Imperio Romano. La muerte de Rosa de los Camborios se 
compara con la muerte de Santa Olalla. La imagen de la guardia civil surgió en la segunda etapa de trabajo con el libro: "Ahora trabajo mucho. Estoy terminando el Romancero Gitano. Nuevos temas y Viejas sugestiones. La Guardia Civil va y viene por toda la Andalucía» (Federico García Lorca Carta a J. Guillén del 2 marzo de 1926) (1962: 1565-1566).

En definitiva, la persecución de los gitanos por la guardia civil se interpreta en la retrospectiva histórica como la persecución de los primeros cristianos por los romanos paganos, o sea, la persecución de los inocentes por los despiadados. L. Ospovat en sus comentarios del Romancero determina la imagen de la guardia en la variante final del libro como una fuerza ciega y cruel, hostil al mundo poético de los gitanos. Esta implacabilidad se hace un tema central en ese libro (1975: 480).

G. Stepanov, analizando el Romancero, comenta que el gitano de Lorca no es un tipo etnográfico que se hizo una parte indispensable del paisaje andaluz, sino que es una imagen social que representa a todos los perseguidos y desheredados independientemente del color de su piel y su localización geográfica. El impulso para creación de este carácter fue una firme posición social del poeta (1979: 11).

En una entrevista Lorca comentó: «El Romancero gitano no es gitano más que en algún trozo al principio. En su esencia es un retablo andaluz de todo el andalucismo. Al menos como yo lo veo. Es un canto andaluz en el que los gitanos sirven de estribillo» (Estampa de García Lorca) (1962: 1659). En su carta a J. Guillén Lorca escribió sobre el Romancero: "Quedará un libro de romances y se podrá decir que es un libro de Andalucía» (1962: 1564). Asimismo en su conferencia-recital dedicada al Romancero Lorca comentó:

El libro en conjunto, aunque se llame gitano, es el poema de Andalucía... Un libro antipintoresco, antifolklórico, antiflamenco, donde no hay ni una chaquetilla corta, ni un traje de torero, ni un sombrero plano, ni una pandereta... y donde no hay más que un solo personaje que es la Pena... pena andaluza que es una lucha de la inteligencia amorosa con el misterio que la rodea y no puede comprender (García Lorca 1994).

El Martirio de Santa Olalla ocupa un lugar especial en este «retablo andaluz». El tríptico es una especie de culminación del libro (Selig 1992: 122). En este poema se vuelve a pensar, analizar, organizar las imágenes de todo el Romancero. No es solo el caso de reestablecimiento de la imagen del pueblo perseguido y bendito por el Señor, sino también la imagen de misma Olalla, la primera Santa Española, se desarrolla como una integra alusión a las Pasiones de Jesucristo, empezando con el grito del gallo y terminando con su resurrección. Un papel importante en este proceso como hemos visto desempeña el color.

Es el segundo romance por la cantidad de colores aplicados (10 usos) después del Romance sonámbulo con sus 26 usos entre los cuales 24 corresponden 
al hiperónimo verde. A pesar de ser uno de los romances más crueles del libro el Martirio, tiene la gama cromática más amplia del Romancero (blanco, negro, verde, gris, rojo, amarillo). Si las primeras dos partes del romance -Panorama de Mérida y El Martirio - llevan todos los colores cromáticos, en la última Infierno y Gloria su uso se reduce a la fama acromática. Esto sirve para crear un contraste entre el mundo terrestre con su dolor y sufrimiento y el mundo celeste con la Gloria de los Santos en la Luz Divina.

\section{Conclusiones}

En definitiva, en el Martirio de Santa Olalla se observan tres niveles de codificación contextual (codificación interior del texto). El primer nivel es una oposición de los antónimos léxicos «blanco» y «negro» que sirven para representar la oposición entre Olalla con su guardia celestial (los blancos) y la guardia romana como la guardia infernal (los negros).

En el segundo nivel, las designaciones contextuales de color «nieve» (blanco) y «noche» (negro) sirven para crear la imagen de un tablero de ajedrez. De tal suerte que la oposición anterior de las fuerzas de la Luz y de la Oscuridad se interpreta desde la perspectiva de una partida de ajedrez.

En el tercer nivel se oponen los significados contextuales de las palabras que permiten llegar a la EP del texto en la que está escondida la fábula implícita del Romancero. Este nivel contiene información ideológica y permite obtener acceso a la posición ética y estética del autor del texto. Esta información muestra que el autor interpreta los acontecimientos del mundo virtual de su Romancero en una retrospectiva histórica. De tal manera, la guardia civil que persigue al pueblo inocente se asemeja a la guardia romana que perseguía a los cristianos.

\section{FUENTES}

DRAE (2014). Diccionario de la lengua española, Real Academia Española. Barcelona: Espasa Libros.

García Lorca, Federico (1962). Obra completa. Madrid: Aguilar.

García Lorca, Federico (1994). «Romancero gitano. Conferencia-recital - 1935», en Federico García Lorca, Obras VI, Prosa 2, Epistolario. Madrid: Akal, pp. 358-366.

García Lorca, Francisco (1972). «Verde», en Homenaje a J. Casalduero: Crítica y poesía. Ofrecido por sus amigos y discípulos. Madrid: Gredos, pp. 135-139.

García-Posada, Miguel (ed.) (1998). «Introducción», en Federico García Lorca, Obras II.

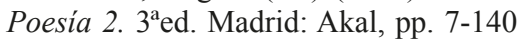

Harris, Derek (ed.) (1993). Romancero gitano. Poeta en Nueva York. El público. Madrid: Taurus.

Hernández, Mario (ed.) (1981). Primer romancero gitano 1924-1927 - Otros romances del teatro 1924-1935. Madrid: Alianza Editorial. 
NGLE (2009). Nueva gramática de la lengua española, Real Academia Española, T. 1, Bosque Muñoz I. (coord.). Madrid: Espasa Libros.

Ospovat, Leo (1975). «Comentarios», en Federico García Lorca, Obras Seleccionadas, T. I, Poesía. Prosa. Obra teatral. Moscú: Judozhestvennaya Literatura, pp. 477-487.

Stepanov, Georgiy (1979). «Federico García Lorca», en Federico García Lorca, Obras Seleccionadas. Moscú: Progress, pp. 5-44.

\section{BIBLIOGRAFÍA CITADA}

Alarcos Llorach, Emilio (2009). Gramática de la lengua española. Madrid: Espasa.

Arango, Manuel Antonio (1998). Símbolo y simbología en la obra de Federico García Lorca. Madrid: Fundamentos.

Balmaseda Maestu, Enrique (1998). «La lengua del Romancero gitano (Federico García Lorca): Comentario lingüístico del Romance sonámbulo», Cuadernos canela. 10, pp. 21-38.

Beltrán Fernández de los Ríos, Luis (1986). La arquitectura del humo: una reconstrucción del «Romancero gitano» de Federico García Lorca. London: Tamesis Books Limited.

Berlin, Brent, y Paul Kay (1969). Basic Color Terms: Their Universality and Evolution. Berkley: University of California Press.

Carroll, Lewis (2003). Alicia en el país de las maravillas. A través del espejo. Madrid: Akal Ediciones.

Cirlot, Juan Eduardo (1992). Diccionario de símbolos. Barcelona: Labor.

Díaz, Roxana (2013). «La verde adivinanza de Lorca», Palabras diversas. 43, pp. 44-55.

Díaz, Roxana (2014). «La Dignidad Roja», Giralda. Boletín del Instituto Iberoamericano de Estudios Andalusies. 2, pp. 55-63.

Dijk, Teun Adrianus van (2009). Society and Discourse. New York: Cambridge University Press.

Dorcus, Roy Melvin (1932). «Habitual Word Association to Colours as a Possible Factor in Advertising», Journal of Applied Psychology. 16(3), pp. 277-287.

Dumitrescu, Domnita (1974). «Sobre la terminología cromática en la poesía de la generación 27», en Actas del Quinto Congreso Internacional de Hispanistas. Bordeaux: Instituto de Estudios Ibéricos e Iberoamericanos. Universidad de Bordeaux III, pp. 345-354.

Eco, Umberto (1990). Obra abierta. Barcelona: Ariel.

Fraser, Tom, y Adam Banks (2004). Designer's Color Manual: The Complete Guide to Color Theory and Application. San Francisco: Chronicle Books.

Grossmann, María (1982). «El sistema léxico-semántico de los términos de colores en castellano, Didattica della lingua e lingue iberiche», Atti del Convegno de l'aquila, 14-15 settembre 1981, pp. 71-88.

Guerrero Ruiz, Pedro y Veronica Dean-Thacker (1998). Federico García Lorca: El color de la poesía. Murcia: Universidad de Murcia.

Henríquez Ureña, Pedro (1919). Antología de la versificación rítmica. México: Editorial México Moderno, S. A.

Herrero, Javier (1992). «"Negros maniquís de sastre”: Death and Resurrection in Lorca's Martirio de Santa Olalla», en Ann L. McKenzie y Dorothy S. Severin (eds.), Hispanic Studies in Honour of Geoffrey Ribbans. Liverpool: Liverpool University Press, pp. 259-265.

Karwoski, Theodore (1944). «Psychological studies in semantics. Part I. Free association reactions to words, drwings and objects», Journal of Social Psychology. 20, pp. 235-247. 
Kolesov, Vladimir (1986). «La luz y el color en el canto medieval ruso Cantar de las huestes de Ígor», en Igor I. Shcliarevsky (ed.), Cantar de las huestes de Ígor: 800 años. Moscú: Sovetskiy Pisatel, pp. 215-229.

Lama, Victor de (ed.) (1997). Poesía de la generación del 27: Antología crítica comentada. México: Editorial EDAF, S. A.

Lotman, Yuri (2011). Estructura del texto artístico. Madrid: Akal.

Pastoureau, Michel (2006). Una historia simbólica de la Edad Media occidental. Buenos Aires: Katz.

Ramsden, Herbert (2008a). «Introduction», en Federico García Lorca, Romancero gitano. Manchester: Manchester University Press, pp. 1-84.

Ramsden, Herbert (2008b). Lorca's Romancero gitano: Eighteen commentaries. Manchester: Manchester University Press.

Riesco Chueca, Pilar (1995). Pasionario hispánico. Sevilla: Publicaciones de la Universidad de Sevilla.

Selig, Karl-Ludwig (1992). «Lorca's 'Santa Olalla' and the Problems of the Text», en Kurt Reichenberger y Alfredo Rodríguez López-Vázquez (eds.), Federico García Lorca: perfiles críticos. Kassel: Edition Reichenberger, pp. 121-125.

Sokolova, Xenia (2014). «The stable comparative constructions with the colorative achromatic component «black» in the romance languages», Boletín de la Universidad de San Petersburgo, Serie Filológica. 13, pp. 402-414.

Southworth, Eric (1999). "On Lorca's San Rafael and other texts», Modern Language Review. 94 (1), pp. 87-102.

Urdeix, Josep (2006). El rito de la misa en el misal de San Pío V: Ordo Missae, Ritus servandus in celebratione Missae. Barcelona: Barcelona Centre de Pastoral Litúrgica.

Wierzbicka, Anna (1990). «The meaning of color terms: semantics, culture, and cognition», Cognitive linguistics, pp. 99-150.

Fecha de recepción: 8 de septiembre de 2016.

Fecha de aceptación: 6 de marzo de 2017. 